\title{
Implications of Dynamic Trading for Insurance Markets
}

\author{
Jose S. Penalva Zuasti* \\ Universitat Pompeu Fabra and CREA \\ Department of Economic and Business \\ Ramon Trias Fargas, 25-27, Barcelona, 08005, SPAIN \\ Phone: +34-93-542-1926 \\ Fax: $+34-93-542-1746$
}

E-mail: jose.penalva@upf.edu

Key Words: full insurance, risk sharing, portfolio choice, welfare, heterogeneity JEL classification: G11, G12, G22, D81

\footnotetext{
* I would like to thank Bryan Ellickson, William R. Zame and Alberto Bisin for their guidance and suggestions. I would also like to thank James Costain, José Luis Fernández Pérez, Manuel Moreno, Albert Satorra and the participants to the 30th EGRIE conference for their questions and comments. I acknowledge financial support from the Ministerio de Ciencia y Economía DGESIC P105-8002, the Generalitat de Catalunya 2001-SGR-00280 and the Fundación BBVA. All errors remain my own.
} 


\begin{abstract}
We study the interaction between insurance and capital markets within a single but general framework. We show that capital markets greatly enhance the risk sharing capacity of insurance markets and the scope of risks that are insurable because efficiency does not depend on the number of agents at risk, nor on risks being independent, nor on the preferences and endowments of agents at risk being the same. We show that agents share risks by buying full coverage for their individual risks and provide insurance capital through stock markets. We show that aggregate risk enters private insurance as a positive loading on insurance prices and despite that agents will buy full coverage. The loading is determined by the risk premium of investors in the stock market and hence does not depend on the agent's willingness to pay. Agents provide insurance capital by trading an equally weighted portfolio of insurance company shares and a riskless asset. We are able to construct agents' optimal trading strategies explicitly and for very general preferences.
\end{abstract}




\section{Implications of Dynamic Trading for Insurance Markets}

Within the financial services industry, insurance and capital markets are usually studied separately and yet they share quite fundamental similarities: they help people control their risk exposures. Insurance allows agents to reduce their exposure to certain risks (losses) while capital markets give people the opportunity to invest in risky assets (with potential gains and losses) in a way that will suit their taste for risk. Over the past two decades we have observed huge growth in capital markets of developed economies: increasingly sophisticated and efficient financial trading mechanisms and a vast growth in the number and type of financial instruments available to the general public. This growth has not been matched by a similar development in primary insurance markets and yet, as capital markets and insurance are so closely related at a fundamental level, one should expect there to be some interactions between the two. The interaction we have observed is increased liberalization of the insurance industry and a slow homogenization of regulation for the entire financial services industry in terms of risk management and solvency requirements.

We are interested in studying the interaction between insurance and capital markets and we do it by putting both markets within a single theoretical framework. In this paper we combine a standard model of primary insurance with a sophisticated model of the stock market. The aim is to study what effect access to financial markets has on the scope and efficiency of a competitive insurance market. At the same time we want to see what can be learnt about capital markets by modelling explicitly the insurance activity driving asset prices.

There is a large literature that addresses the issue of insurance market scope and efficiency. A classic result that underlies much of current intuition on this issue is the work of Malinvaud $(1972,1973)$ : insurance contracts deal with individual risk and not aggregate risk (the risk to the whole economy); insurance markets will be efficient in the absence of future commodities and contingent commidities if the individual risks do not generate aggregate risk for the economy. This will occur if 
there are sufficiently many private risks so that the law of large numbers applies, and on aggregate the risk disappears (in the limit). Since this work, a large body of literature has analyzed how could insurance markets function efficiency when aggregate risk does not disappear, e.g. when there are large natural catastrophes such as earthquakes or hurricanes.

The literature has come up with many answers but we will limit ourselves to a small list of illustrative references. One of them is that aggregate risk sharing is built into insurance industry structure (Dionne and Doherty (1993) uses this argument to explain the high proportion of mutuals relative to stock companies in the insurance sector - despite their higher capital costs as documented in Harrington Niehaus (2002)). Another answer is to have aggregate risk incorporated into insurance contract design (Cummins Mahul (2001), Cass Chichilninsky and $\mathrm{Wu}(1996))$. Some argue that aggregate risk is dealt with in secondary markets such as reinsurance (Borch (1984), Doherty Tiniç (1981), Froot (2001), Jaffee Russell (1997), Zanjani (2002)) and other financial markets (Ellickson Penalva (1997), Harrington Niehaus (1999), Aase (2001), Christensen et al (2001)). While others have focused of what the presence of an insurable risk will do to agents' insurance and investment decisions (Doherty Schlesinger (1983), Gollier (1994), Vercammen (2001)).

This paper is within the line of research that studies how secondary markets (specially stock markets) aid optimal risk sharing. It contributes to the literature by providing a relatively simple and general structure that permits the joint study of standard insurance and finance models and their interactions. The structure is based on the one in Penalva (2001) but with a very different insurance sector. Here we consider more natural insurance markets where contracts are illiquid, i.e., they cannot be dynamically traded. Within this new structure we show that the presence of sophisticated financial markets enhances the scope for optimal risk sharing via insurance when there is aggregate risk. Using results from financial theory we show that agents use their ability to trade frequently in the stock market to optimally share aggregate risks such as those arising from earthquakes. We show that insurance markets can be efficient even if there are very few risks and the risks are not independent. Also, insurance markets are efficient even 
if agents in the economy have very different wealth levels and tastes for risk. Our model also extends existing results by providing an exact characterization of stock market trading behavior. In particular, we are able to show that when there are only simple risks agents will only require access to an equally weighted portfolio of insurance company shares and a riskless asset, and that the trading strategies in these assets are very simple to construct (and do not require solving complex stochastic differential equations in the line of Merton $(1969,1971)$ or dynamic programming, Samuelson (1969)).

We also find that aggregate risk enters the primary insurance market via prices and not through insurance demand: equilibrium premia in the secondary market, the stock market, determine premia in direct insurance. This feedback between primary and secondary markets via the loading on insurance prices is a natural characteristic in our economy. The idea that such connection exists has been put forward by other authors in the context of reinsurance markets (and with very different models), e.g. in Borch (1984). In our model ${ }^{1}$ the stock market is the only secondary market for insurance contracts - reinsurance is redundant because there is no risk of default. As we will show, the loading will not depend on the insured's willingness to pay but on the overall economy's taste for risk.

The presence of a stock market can greatly simplify people's demand for insurance: they will want to eliminate all the risk from their private accidents and hence buy full coverage - even when competitive insurance prices have a positive loading (i.e. they are priced above their actuarially fair price) to compensate investors in capital markets. Our results illustrate how the presence of a developed stock market can radically alter our perception of how insurance markets operate.

The paper is structured as follows: this introduction is followed by a detailed description of the model: first we describe the agents and their risks, then the insurance market followed by the stock market, and after that we put them together to define agents' budget constraints and the corresponding notion of equilibrium. The next section contains a partial equilibrium analysis of optimal insurance demand. Insurance market efficiency is then proven in section 3, and

\footnotetext{
${ }^{1}$ As already seen in Doherty and Tiniç (1981)
} 
we study the corresponding insurance and asset demand in section 4 . Section 5 discusses how the results extend to insurance markets with more complex risks and considers what will happen if agents have special preferences (of the type commonly used in financial models). We then provide some concluding remarks.

Only the short and simpler proofs are in the text, the rest we have put in the appendix.

\section{A SIMPLE MODEL OF INSURANCE WITH DYNAMIC TRADING}

We construct two economies: one is a simple economy where all agents are the same and exposed to independent risks; the other is more complex and is used to show that the results of our paper apply more generally (in the general economy agents can have different preferences and endowments, and risks do not have to be independent). The simpler economy is presented to illustrate our results in a framework that is familiar to economists working with risk and insurance. The reader wishing to focus on this simpler economy can skip the more technical paragraphs which are used for the general case. The model itself is a contribution to the literature because of the way it incorporates the time dimension into a standard economy with personalized risks. In the model agents can consume at dates zero and one; date one endowment is at risk but agents have the accidents (which reduce their future endowment) at some intermediate date $t \in[0,1]$. Because our model is unusual we provide additional intuitive explanations of its different parts and how they interact.

\subsection{Preferences and Risk}

We analyze an economy with $n<\infty$ agents. Agents can consume at date 0 and date 1 . In the standard insurance model all agents have the same preferences and endowments. Agents are expected utility maximizers with common priors and their preferences are given by:

Assumption A.1 For all $i=1, \ldots, n, U_{i}(x)=u(x(0))+\beta E(u(x(1)))$, where $u$ is an increasing, strictly concave differentiable function satisfying the standard Inada conditions.

A more general version of preferences which we will also consider is: 
Assumption B.1 For all $i=1, \ldots, n, U_{i}(x)=u_{i}(x(0))+\beta_{i} E\left[v_{i}(x(1))\right]$, where both $u_{i}$ and $v_{i}$ are increasing, strictly concave differentiable functions satisfying the standard Inada conditions.

Agents' date one endowments are risky in the sense that if an agent has an accident his date one endowment will be lower. Agent $i$ 's endowment is denoted $e_{i} \equiv\left(e_{i}(t)\right)_{t \in\{0,1\}}$, the aggregate endowment is denoted $e \equiv(e(t))_{t \in\{0,1\}}, e(t)=$ $\sum_{i=1}^{n} e_{i}(t)$, and we use the random variable $N_{i}(1)$ to count the number of accidents suffered by agent $i$, so that $N_{i}(1)$ can take values 0 or 1 . The standard assumption is:

Assumption A.2 All agents have the same endowments and they will have a date one endowment loss of magnitude $L<w$ with probability $p$ (independent across agents) so that $e_{i}(0)=w>0$ and $e_{i}(1)=w-N_{i}(1) L$.

It will be useful to keep track of the total number of accidents in the economy: $N(1)=\sum_{i=1}^{n} N_{i}(1)$.

\subsection{Insurance and the stock market}

Insurance markets and the stock market interact in this model as agents can purchase private insurance and invest in the stock market. The link between the two is provided by insurance companies who sell insurance and issue shares. We combine standard models of both activities from insurance and finance theory.

Agents can buy insurance to compensate them for losses from accidents. Agent $i$ faces a price per unit of coverage denoted $S_{i}^{I}$ and can choose his optimal level of coverage $\alpha_{i}$. The endowment net of insurance will be: at date zero $e_{i}(0)-\alpha_{i} S_{i}^{I}$, and at date one $e_{i}(1)+N_{i}(1) \alpha_{i}$, which in the standard insurance model are $e_{i}(0)=w-\alpha_{i} S_{i}^{I}$ and $e_{i}(1)=w-N_{i}(1)\left(L-\alpha_{i}\right)$.

Stock markets are slightly more complex to model. We first define an insurance company and the stock market. Then describe the interaction between share prices and information.

An insurance company is an institution whose objective is to sell private insurance contracts and raise capital to cover future indemnity payments. It can raise capital by issuing shares and by borrowing from the money market. To simplify the exposition we will assume there are $J$ insurance companies. Each company issues one perfectly divisible share. Companies are fully equity financed. They 
invest the insurance premia in a riskless bond and at date one issue dividends equal to the firm's assets (premia plus interest) minus indemnities payable. Because we do not allow default the owners of insurance firms stand to loose money if there are too many accidents and will require compensation for taking this risk.

The stock market is an institution in which an auctioneer continuously sets prices to facilitate share trading. We assume there is no private information and the auctioneer sets prices such that no arbitrage opportunities exist. Agents can go to the stock market and trade shares at the announced prices at any time without any costs, frictions or constraints. As agents have common priors, trades are purely motivated by the desire to control risk exposures.

The relevant information in this market is agents' accidents (or lack thereof). We assume that an accident to agent $i$ can happen at any time between consumption periods and we denote the random time of the accident to $i$ by $\tau_{i} \in[0,1]$. Although the consequences of the accident on $i$ 's endowment will not be realized until date one, that information will have an immediate effect on share prices as it reveals information on future insurance company liabilities (and hence future dividends).

We assume that for each agent $i$ the arrival time of an accident is a smooth function of calendar time. More specifically, if $\tau_{i}$ is the time that agent $i$ suffers an accident, $\tau_{i}$ is distributed as an exponential distribution with parameter $\lambda$ (naturally, $\tau_{i}>1$ implies agent $i$ suffers no accident at date one, i.e. $\left.N_{i}(1)=0\right)$. Under Assumption A.2 agents' risks are independent so that the parameter $\lambda$ is related to $p$ via the following equation:

$$
p=1-\exp (-\lambda) \Leftrightarrow \quad \lambda=-\ln (1-p)
$$

A more general possibility is to assume that agents' risks are not completely independent. For this generalization we need to introduce some formal concepts and notation. Here we provide a brief intuitive explanation and all the technical details are given in Appendix A.1. We assume there is a probability space $\left(\Omega^{\prime}, \mathcal{F}_{1}, P\right)$ describing all uncertainty in the economy, where $\Omega^{\prime}$ represents all the states of the world (including the number of accidents and the corresponding arrival times) and $\mathcal{F}_{1}$ represents all the information that will be revealed up to 
date one. A set $A \subseteq \Omega^{\prime}$ is an event and $P$ is the probability measure that tells us how probable any event $A$ is. We use $\mathbf{1}_{A}$ to denote the indicator function of an event $A$, i.e. for all $\omega \in \Omega, \mathbf{1}_{A}(\omega)=1$ if $\omega \in A$ and zero otherwise. All agents have common priors so they agree on $P . E_{P}[x]$ represents the expectation of the random variable $x$ with respect to measure $P$. Given a stochastic process $(x(t))_{t \in[0,1]}$, define for any $t \in[0,1]$ the random variable $x(t-) \equiv \lim _{s \uparrow t} x(s)$. In the stock market, as we saw earlier, the information that drives prices is accident information. We keep track of this information with the processes $\left(N_{i}(t)\right)_{i=1}^{n}$ and $N(t)$, where $N_{i}(t)$ counts the number of accidents that have occurred to agent $i$ up to (and including) date $t$ and $N(t)=\sum_{i=1}^{n} N_{i}(t)$ counts the total number of accidents for the whole economy. All the information generated by $\left(N_{i}(t)\right)_{i=1}^{n}$ is public information and is formally described by the filtration $\left(\mathcal{F}_{t}\right)_{t \in[0,1]}$.

In the general case with non-independent risks we assume that accidents are subject to possible contagion effects:

Assumption B.2 All agents will have a date one endowment loss of magnitude $L<w_{i, 1}$ with probability $p$ so that $e_{i}(0)=w_{i, 0}>0$ and $e_{i}(1)=w_{i, 1}-$ $N_{i}(1) L$. The distribution of accident arrivals is described by a hazard rate $\lambda_{i}(t)=g(t, N(t-)) \mathbf{1}_{\left\{N_{i}(t-)=0\right\}}$.

When agents' risks are independent $\lambda_{i}(t)=\lambda \mathbf{1}_{N_{i}(t-)=0}$ - i.e. after an accident, when $N_{i}(t)=1$, agent $i$ is no longer at risk and his hazard is zero. In the general case, using function $g(t, N(t-))$ instead of the constant $\lambda$ allows two effects: one, a non-time homogenous hazard rate, e.g. an accident can be more (less) likely at the beginning (at the end) of the trading period ([0, 1]); and two, the hazard rate can depend on $N(t-)$, i.e. on the current total number of accidents. The latter effect allows us to model contagion by allowing the hazard rate to increase (or fall) as the number of accidents in the economy increases.

Each of the $J$ insurance companies sells insurance to a set of agents. $I_{j}$ is the set containing the indices which identify the agents that buy insurance from firm $j$.

There are two types of dynamically traded assets: insurance company shares, and a zero coupon bond. Any dynamically traded asset is formally described by a final dividend $d_{j}$ and a stochastic price process $S_{j}(t)$, with $S_{j}(1)=d_{j}$. As the 
auctioneer sets prices so that there are no arbitrage opportunities, by Harrison and $\operatorname{Kreps}(1979)$, there exists a probability measure $Q$ on $\left(\Omega^{\prime}, \mathcal{F}^{\prime}\right)$ and an interest rate process $r(t)$ such that for all $j$,

$$
\forall t \in[0,1], \quad S_{j}(t)=E_{Q}\left[d_{j} e^{-\int_{t}^{1} r(s) \mathrm{d} s} \mid \mathcal{F}_{t}\right] \quad P-\text { a.s. }
$$

We will use the notation $\mathbf{r}=\int_{0}^{1} r(t) \mathrm{d} t$ for the interest rate, and $\mathcal{D}=\left(S_{j}(t)\right)_{j=0}^{J}$ for the set of assets in stock markets (where $S_{0}(t)$ refers to the bond and $S_{j}(t)$ to the shares of insurance company $j=1, \ldots, J)$.

All these preliminaries allow us to formalize different economies with risk and compare different types of economic institutions. We will distinguish economies in terms of the set of assumptions on preference-endowment pairs and we will also distinguish between an economy with only state-contingent commodity markets and one with asset markets. We will consider two types of state-contingent commodities depending on whether both assumptions A.1 and A.2 hold (economy $\mathcal{E}(A)$ ), or whether both B.1 and B.2 hold $(\mathcal{E}(B))$. A state-contingent economy, e.g. $\mathcal{E}(A)$, is distinguished from the same economy with asset markets by explicitly including the set of assets in the description of the economy ${ }^{2}, \mathcal{E}(A, \mathcal{D})$. The basic economy which integrates insurance and financial markets is $\mathcal{E}(A, \mathcal{D})$. In this economy everyone has the same preferences and risk and everyone can buy private insurance coverage and invest in a bond and insurance company shares.

\subsection{The budget constraint}

We now define what consumption allocations agent $i$ can achieve. In terms of insurance, agent $i$ can buy as much (non-negative) coverage as he wishes, $\alpha_{i} \in$ $\mathbf{R}^{+}$. As for possible investment strategies, given prices $\mathcal{D} \equiv\left(\left(S_{j}(t)\right)_{t \in[0,1]}\right)_{j=0}^{J}$, let agent $i$ 's investment strategy in asset $j$ be represented by $\theta_{j}^{i}(t)$ where $\theta_{j}^{i}(t)$ is the number of units of asset $j$ agent $i$ plans to hold going into date $t$. The set of allowable investment strategies is denoted by $\Theta$ and it does not allow trades to anticipate information or to hold an infinite amount of any asset. We also assume

\footnotetext{
${ }^{2}$ We do not explicitly include the private insurance contracts in the description of asset markets to reduce notation. If there are asset markets then there are insurance markets as well.
} 
that allowable trading strategies do not imply adding or reducing wealth ${ }^{3}$ between dates 0 and 1.

We assume that the shares of insurance companies are part of the agents' endowments; let $\theta_{j, 0}^{i}$ denote the number of units of asset $j$ agent $i$ is endowed with at date zero. Agent $i$ 's initial endowment now is $e_{i}(0)=w+\sum_{j=1}^{J} \theta_{j, 0}^{i} S_{j}(0)$.

With these elements we can now define agent $i$ 's budget constraint given asset and insurance prices, $B_{i}\left(\mathcal{D}, S_{i}^{I}\right)$ :

$$
B_{i}\left(\mathcal{D}, S_{i}^{I}\right)=\left\{\begin{array}{l|l}
x=(x(0), x(1)) & \begin{array}{l}
\exists \theta^{i} \in \Theta, \alpha_{i} \in \mathbf{R}^{+} \\
x(0)=e_{i}(0)-\alpha_{i} S_{i}^{I}-\sum_{j=0}^{J} \theta_{j}^{i}(0) S_{j}(0) \\
x(1)=e_{i}(1)+\alpha_{i} N_{i}(1)+\sum_{j=0}^{J} \theta_{j}^{i}(1) d_{j}
\end{array}
\end{array}\right\}
$$

\subsection{Insurance Market Equilibrium}

We want to study the effects on insurance of having sophisticated financial markets. The approach we follow here is to compare what happens in an economy with insurance and other assets with an economy with state-contingent commodity markets. The first welfare theorem tells us that the equilibrium allocations in the state-contingent commodity economy will be Pareto efficient. If those allocations can be attained as an equilibrium with insurance and financial assets then we can say that insurance markets are efficient. In order to determine the effect of financial assets we have to compare the economy with financial assets to one without.

We know from Arrow's pioneering work (Arrow 1964) that without dynamic trading one needs $2^{n}$ financial assets to obtain the state-contingent equilibrium of $\mathcal{E}(A)$ as a financial markets equilibrium. From Malinvaud (1973) we obtain that insurance without financial markets will not be efficient in general. This is because there are only $n$ insurance contracts to deal with both individual risk and aggregate risk. As $n$ gets larger then by the law of large numbers the aggregate risk disappears and only then will the $n$ insurance contracts suffice. Duffie and

\footnotetext{
${ }^{3}$ This is a condition arising from the budget constraint but we include it in the definition of allowable trading strategies to simplify the presentation.
} 
Huang(1985) extend Arrow(1964) to markets with dynamic trading and asset market equilibrium (as defined by Radner (1972)). Allowing for dynamic trading reduces the number of assets needed, namely you need at most $K+1$ 'appropriate' assets. The value of $K$ is a fixed number, determined by the underlying stochastic process. In Appendix A.2 we demonstrate that for our economy $K=n$. We want to explore what this dynamic trading does for insurance markets.

State-contingent equilibrium (Arrow-Debreu equilibrium) is a standard concept so we will not define it here, but we do need to define an equilibrium for insurance markets. The notion of equilibrium we want to use is one in which agents are making their consumption, insurance and trading decisions in an optimal manner, given insurance and asset prices. These prices, set by the auctioneer, have to lead to market clearing in the goods market. Also, these prices cannot allow arbitrage opportunities in asset trading. We also require that private insurance markets are competitive.

Above we related relation (1) and no arbitrage opportunities. Here we need to define what we mean by competitive insurance pricing: we say that insurance prices are competitive under $(Q, r)$ if for all $B \subseteq\{1, \ldots, n\}$, one can construct $(S(t), d)$ satisfying relation (1) such that $S(0)=\sum_{i \in B} S_{i}^{I}$ and $d=\sum_{i \in B} N_{i}(1)$.

This condition states, literally, that every possible combination of individual risks sold as an asset in the stock market will satisfy the no-arbitrage condition. We do not believe standard no-arbitrage arguments apply here for illiquid insurance contracts but this condition will hold as a result of competition (e.g. Bertrand-type successive price cutting). Private insurance markets are defined by firms that issue private insurance and finance the risks through the stock market. Consider a company selling insurance above equilibrium prices, i.e. $S_{i}^{I}+\epsilon$, with $\epsilon>0$. The market value of the liabilities from the insurance contract at date zero are $e^{-\mathbf{r}} E_{Q}\left[N_{i}(1)\right]$ so that the manager of the firm can compensate investors and retain $\epsilon$ from each insurance contract. This $\epsilon$ attracts another manager who can offer insurance at $S_{i}^{I}+\epsilon / 2$. The new manager will drive out the old one at a profit. This undercutting will continue until insurance is offered at its market value $S_{i}^{I}$ and the initial value of every insurance company will be zero. Note that it is not reasonable for a manager to sell insurance at a price below $e^{-\mathbf{r}} E_{Q}\left[N_{i}(1)\right]$ 
as he will need to add money from his own pockets to compensate investors if he is going to raise enough capital.

Definition 1.1. A triple $\left.\left(\left(x_{i}\right)_{i=1}^{n},\left(S_{i}^{I}\right)\right)_{i=1}^{n}, \mathcal{D}\right)$ is an insurance market equilibrium if:

(i) for all $i=1, \ldots, n, x_{i} \in B\left(\mathcal{D}, S_{i}^{I}\right)$ and for all $x^{\prime} \in B\left(\mathcal{D}, S_{i}^{I}\right), U_{i}\left(x_{i}\right) \geq U_{i}\left(x^{\prime}\right)$;

(ii) there exists $(Q, r)$ such that every $S_{j} \in \mathcal{D}$ satisfies Relation (1); and

(iii) insurance prices are competitive.

Remark 1. 1. There exists an insurance market equilibrium $\left.\left(\left(x_{i}^{*}\right)_{i=1}^{n},\left(S_{i}^{I}\right)\right)_{i=1}^{n}, \mathcal{D}\right)$ such that $\left(\left(x_{i}^{*}\right)_{i=1}^{n}\right)$ is Pareto optimal for $\mathcal{E}$.

Without any restrictions on the set of dynamically traded assets, $\mathcal{D}$, we can get this result just by ensuring that $\mathcal{D}$ contains enough appropriate securities as in Duffie Huang(1985). But this is not our objective; we want to address the interaction between insurance and asset markets and its implications for insurance. In particular, we want to say something more precise about the interaction of $\mathcal{D}$ with insurance and about the way agents trade in this economy.

\section{OPTIMAL INSURANCE AND TRADING}

The first question we consider is how the presence of additional investment opportunities (the stock market) affects insurance decisions in competitive insurance markets.

We know (e.g. Smith Mayers (1983)) that in general the optimal amount of coverage will depend on the interaction between indemnity payments and the returns on the rest of the assets in the economy. We will show that competitive insurance markets can result in the demand for insurance being independent of the returns of other investments. Furthermore, this demand for insurance will be a demand for full insurance coverage. We look at competitive insurance markets in economies that satisfy two additional conditions: (i) only undiversifiable risk carries a risk premium, and (ii) agents can tailor their exposure to aggregate risk. For $t \in[0,1]$ and measures $P$ and $Q$, let $P_{t}$ and $Q_{t}$ define the restriction to $\left(\Omega^{\prime}, \mathcal{F}_{t}\right)$ of $P$ and $Q$ respectively. 
Definition 2.1. In economy $\mathcal{E}$, a measure $Q$ is said to price only aggregate risk if there exists a real-valued function $f$ such that $\xi(1)=f(e(1))$ where

$$
Q(\omega)=P(\omega) \xi(1, \omega) ; \quad \xi(t, \omega)=\frac{\xi(1, \omega)}{E_{P}\left[\xi(1) \mid \mathcal{F}_{t}\right]} \equiv \frac{\mathrm{d} Q_{t}}{\mathrm{~d} P_{t}}(\omega)
$$

Definition 2.2. In economy $\mathcal{E}$, a set of assets $\mathcal{D}$ is said to span aggregate uncertainty if for every consumption allocation $x$ such that $x(1)=f(e(1))$ there exists $\theta \in \Theta$ and

$$
x(1)=\sum_{j=0}^{J} \theta_{j}(0) S_{j}(0)+\int_{0}^{1} \sum_{j=0}^{J} \theta_{j}(t) \mathrm{d} S_{j}(t)
$$

If measure $Q$ prices only aggregate risk then the price of an asset depends only on its relationship with aggregate risk. If some arbitrary given set of assets spans aggregate uncertainty then the agent is free to transfer consumption between different realizations of aggregate uncertainty arbitrarily. Under these conditions we can establish the relationship between insurance and investments in an economy with competitive insurance markets even if it is not in equilibrium.

THEOREM 2.1. In economy $\mathcal{E}(B)$, with prices $\left(\mathcal{D}, S_{i}^{I}\right)$, agent $i$ 's optimal insurance demand includes buying full insurance if:

(i) the set of assets $\mathcal{D}$ span aggregate uncertainty;

(ii) there exists $(Q, r)$ such that $\mathcal{D}$ satisfy Relation 1 and $Q$ prices only aggregate risk; and, (iii) insurance prices are competitive under $(Q, r)$.

Corollary 2.1. Under the conditions of Theorem 2.1 every agent can make his optimal investment decision independently of his demand for insurance.

Thus, if an economy has a sufficiently effective stock market (in terms of what agents can achieve using the assets traded in that market) and if the investors in that economy only care for aggregate risk then we should observe some very 
special behavior in competitive insurance markets: we should observe people buying full insurance.

We are familiar with the idea that the purchase of full insurance is intimately tied to actuarially fair prices (prices equal to the expected value of future indemnity payments) - but is it the case that if we observe full insurance it means that insurance prices are actuarially fair? Also, we want to know how stringent conditions (i) and (ii) are. Condition (ii) seems quite general, but how about condition (i)? To answer these questions we construct efficient insurance market equilibria.

\section{INSURANCE EFFICIENCY AND EQUILIBRIUM}

We have seen above (Remark 1.1 and related discussion) that markets will be complete with dynamic trading of $n+1$ assets and agents will be able to achieve efficient allocations. We have just shown that under certain conditions agents can attain their optimal allocations by buying insurance and trading assets that span aggregate uncertainty. Putting these two results together we obtain the following new results: (a) the number of assets in $\mathcal{D}$ can be just two (not $n$ ); and, (b) we can be very specific about what these two assets are - they turn out to be very intuitive ones: a zero coupon bond and an equally-weighted portfolio of insurance company shares.

THEOREM 3.1. For economy $\mathcal{E}(B)$, there exists an insurance market equilibrium $\left.\left(\left(x_{i}^{*}\right)_{i=1}^{n},\left(S_{i}^{I}\right)\right)_{i=1}^{n}, \mathcal{D}\right)$ such that $\left(\left(x_{i}^{*}\right)_{i=1}^{n}\right)$ is Pareto optimal for $\mathcal{E}(B)$ with $\mathcal{D}$ containing only two assets: a zero coupon bond and an equally weighted portfolio of insurance company shares.

Corollary 3.1. The standard insurance market economy, $\mathcal{E}(A)$, with aggregate risk only requires dynamic trading in an equally weighted portfolio of insurance company shares and a riskless bond to be efficient.

Insurance markets can be efficient, even if there is aggregate risk, when the economy has a sophisticated stock market. And, the stock market does not have 
to allow trading in very many different assets. In fact, it only needs to have an equally weighted share index and a riskless bond. The presence of such a stock market eliminates not only the need for the law of large numbers to apply but also independence between risks. An economy can have efficient insurance markets even if it is exposed to large risks such as natural disasters (earthquakes and hurricanes). Insurance markets for risks such as satellite launches can function efficiently even though the number of risks is very small and not independent ${ }^{4}$.

\section{INSURANCE AND TRADING IN EQUILIBRIUM}

Having established efficiency we now turn to our earlier result on the effect of stock markets on insurance. If Theorem 2.1 (and its Corollary) hold then in equilibrium agents will buy full insurance. We show that not only is this true but also that we can be very specific about how agents trade the portfolio and the bond in the stock market; we can write down very explicitly what those trades will be.

THEOREM 4.1. In the insurance market equilibrium of Theorem 3.1 the trades of every agent $i$ are characterized by:

a. buying full insurance: $\alpha_{i}=L$;

b. dynamically trading an equally-weighted portfolio in insurance company shares and a bond according to strategies $\theta_{M}^{i}(t)$ and $\theta_{0}^{i}(t)$ respectively. These strategies are constructed using $n+1$ deterministic functions $\hat{\theta}_{M}^{i}(t, j)$ and $\hat{\theta}_{0}^{i}(t, j)$ as follows:

$$
\begin{aligned}
\theta_{M}^{i}(t) & =\sum_{j=0}^{n} \mathbf{1}_{\{N(t-)=j\}} \hat{\theta}_{M}(t, j) \\
\theta_{0}^{i}(t) & =\sum_{j=0}^{n} \mathbf{1}_{\{N(t-)=j\}} \hat{\theta}_{0}(t, j)
\end{aligned}
$$

The $\hat{\theta}$ functions are constructed in Appendix A.4.

There are two important new results here. One relates to insurance demand and the other to investment decisions. In terms of insurance demand, we have shown that Theorem 2.1 (generalized purchase of full coverage) and Corollary 2.1

\footnotetext{
${ }^{4}$ In the case of satellite launches accidents can be a function of the launching technology that changes with time and the number of accidents.
} 
(independence of insurance and investment decisions) apply in equilibrium with very few and natural assets.

As for investment decisions, we would like to emphasize that there are no results in the literature that we know of that characterize trades as we do (both in terms of the exact assets (an equally weighted portfolio of shares and the bond) and the related trading strategies). There are known explicit solutions for continuous trading behavior for given asset price processes but these are limited to models where agents have very specific preferences (of the Hyperbolic Absolute Risk Aversion, HARA, type; we discuss these preferences in the Extensions Section). Solutions for the optimal trading rule with general preferences are for the most part stated either in terms of the value function or as a stochastic differential equation (for approaches based on martingale methods). Essentially what we do is provide an explicit solution to the stochastic differential equations obtained using martingale methods, which in our model turn out to have particularly simple structure and which can be easily computed.

There is still a final question that we want to address and that is: what is the relationship between the equilibrium full insurance decision and the price of insurance. Insurance prices in equilibrium are fair if the price per unit of coverage equals the (discounted) probability of the loss. The difference between the price and the fair value if described using a loading factor. If the price per unit of coverage for agent $i$ is $S_{i}$ and $p$ is the probability of loss, then the loading $\gamma_{i}$ is defined from the following relation: $S_{i}=p\left(1+\gamma_{i}\right) e^{-\mathbf{r}}$. We can show that the loading will be strictly positive and independent of $i$.

TheOREM 4.2. For the equilibrium of economy $\mathcal{E}(B)$ in Theorem 3.1, the price per unit of coverage for all $i \in I$ is the same, $S_{i}^{I}=S$, and it has a strictly positive loading, i.e. $\gamma>0$ where

$$
S=p(1+\gamma) e^{-\mathbf{r}}
$$

This breaks the link between full insurance and fair pricing as we understand it today. If we observe people buying full insurance we cannot conclude that prices are fair. Furthermore, if people purchase full coverage and prices are known to 
be unfair it does not mean that people are irrational or have strange preferences. Full insurance and unfair prices are a characteristic of equilibrium behavior in competitive markets when agents have access to stock markets.

Theorem 4.2 also has an important implication for how insurance prices are determined, namely

COROllary 4.1. The competitive price of private insurance does not depend on the insured's willingness to pay for coverage.

The price of insurance for agent $i, S_{i}^{I}$, depends only on its actuarially fair value, $p$, the loading $\gamma$ determined from the market price for risk (see Appendix A.5), and the market interest rate, $\mathbf{r}$.

\section{EXTENSIONS}

One might naturally ask what the effect is of having only one type of risk (defined by $\lambda_{i}(t)$ and $L$ ). Although this model is different from the one in Penalva (2001), we can use his analysis of aggregate risk and actuarial heterogeneity in our context. In Penalva(2001), each additional risk each agent is exposed to will require an additional insurance contract. In our case that is not necessary as one can write a single insurance contract that will cover all risks. To see this consider car insurance (without a deductible). A car can have very different types of accidents ranging from total damage to a scratch. If the conditions of Theorem 2.1 hold, agents will only need a single standard full coverage contract as opposed to one per different loss magnitude. On the other hand, condition (i) may not be satisfied with only one portfolio of insurance shares. The results in Penalva (2001) suggest that one may need as many as one distinct portfolio per type of risk.

A second extension is to consider only preferences of a certain kind. The usual class of preferences used in financial models are those that have hyperbolic risk aversion (HARA). We show that if agents have preferences of this type then stock market trading behavior is very simple:

Proposition 5.1. If agents' preferences in $\mathcal{E}(B)$ are of the form

$$
U_{i}(x)=v_{i}(x(0))+\beta_{i} E\left(u_{i}(x(1))\right),
$$


where $-u_{i}^{\prime}(x) / u_{i}^{\prime \prime}(x)=a_{i}+b x$, and if agents have access to a bond, full insurance and an equally-weighted portfolio of insurance company shares, then agents' optimal investment strategies are to buy-and-hold the bond and the portfolio and purchase full coverage.

This can be easily shown using a well-known result, namely that the optimal risk sharing rule is linear (see Huang and Litzenberger(1988) p.135 for a very nice proof of this). This means that for all $i$ there exists $\kappa_{i} \in \mathbf{R}$ such that $x_{i}^{*}(1)=\kappa_{i} e(1)$. We know that the equally weighted portfolio and the aggregate endowment are linear functions of $N(1)$ (see the proof of Theorem 3.1 in Appendix A.4), i.e. $d_{M}=\alpha+\beta N(1)$ for some $\alpha, \beta \in \mathbf{R}$, and $e(1)=\alpha_{e}+\beta_{e} N(1)$ for some $\alpha_{e}, \beta_{e} \in \mathbf{R}$.

Putting these together the agent can replicate the optimal risk sharing rule by buying full coverage and investing $\theta_{0}$ in the bond and $\theta_{M}$ in the portfolio, where $\theta_{0}$ and $\theta_{M}$ solve:

$$
\left\{\begin{aligned}
x_{i}^{*}(0) & =w_{i, 0}-S_{i}^{I} L-\theta_{0} S_{0}(0)-\theta_{M} S_{M}(0) \\
\kappa_{i}\left(\alpha_{e}+\beta_{e} N(1)\right) & =w_{i, 1}+\theta_{0}+\theta_{M}(\alpha+\beta N(1)) \\
x_{i}^{*}(0) & =w_{i, 0}+E_{Q}\left[w_{i, 1}\right] e^{-\mathbf{r}}-\kappa_{i} E_{Q}[e(1)] e^{-\mathbf{r}}
\end{aligned}\right.
$$

By some simple algebraic manipulation

$$
\theta_{M}=\frac{\kappa_{i} \beta_{e}}{\beta}, \quad \theta_{0}=\alpha_{e} \kappa_{i}-w_{i, 1}-\alpha \frac{\kappa_{i} \beta_{e}}{\beta}
$$

Note that Proposition 5.1 is proven without reference to risks and it implies no dynamic trading. Hence, Proposition 5.1 holds even if there are many different types of risks.

\section{CONCLUDING REMARKS}

In order to study the interaction between insurance and financial markets we have constructed a relatively simple theoretical framework that encompasses both industries. We have shown that the presence of stock markets where agents can trade dynamically greatly enhances optimal risk sharing via insurance markets. 
This is because agents use stock markets for dealing with aggregate risk and insurance for their private accidents. We have shown that the efficiency of insurance markets does not depend on having agents with the same tastes for risk or same wealth levels. Even risks do not have to be independent as long as agents can trade in financial assets. Also, the financial assets needed are neither many nor complex, so that an economy can achieve optimal risk sharing with relative ease.

The way we model the risks underlying share prices enables us to be very specific about how agents trade, and to construct exact trading rules for economies with very general preferences and continuous trading, something that is rare in the literature. Also, in the last section, we showed that the standard finance assumption of HARA preferences leads to very simple trading strategies and no dynamic trading.

Our model allows us to look at the insurance market in detail and the presence of the stock market greatly simplifies what we observe. Agents separate insurance from investment decisions and purchase full coverage even if the presence of aggregate risk pushes insurance prices above actuarially fair levels.

Overall, our results suggest that the development of financial markets and financial innovation is highly beneficial for insurance markets. Increasing the investor base and providing cheap and flexible investment opportunities enhances the possibilities for insurance companies to increase the number and types of risks insured so that it can develop with the rest of the economy and provide coverage for such risks as satellite launches and earthquake damage to microchip manufacturing plants. 


\section{APPENDIX}

\section{A.1. FORMAL DEFINITIONS}

The Inada conditions on an increasing function $u: \mathbf{R}_{+} \rightarrow \mathbf{R}$ are: $\inf _{x} u^{\prime}(x)=0$ and $\sup _{s} u^{\prime}(x)=+\infty$. Note that this condition is sufficient though not necessary for the results in the paper (they are used to guarantee existence and representative agent characterization of prices), and can be extended to economies with more general preferences in the standard way.

Let $\tau_{i}$ be the random time $\tau_{i} \in[0,1]$ agent $i$ has an accident and if agent $i$ has no accidents between dates zero and one let $\tau_{i}=\infty$. Let $\mathcal{T}=[0,1] \cup$ $\{\infty\}$. The set of states of the world, $\Omega^{\prime}=\mathcal{T}^{n}$ (a standard measurable space). The hazard rates $\left(\lambda_{i}(t)\right)_{i=1}^{n}$ define a probability measure $P$ on $\Omega^{\prime}$. Clearly, $\Omega^{\prime}$ is uncountable. Equivalently, we could have defined $\Omega^{\prime}$ using the space of counting functions $\left(N_{i}(t)\right)_{i \in I}$ on $[0,1]$ - for a more detailed discussion on these issues see Bremaud(1981). Throughout the paper we use the definition of $\Omega^{\prime}$ (in terms of counting functions or stopping times) that is more convenient or intuitive for the context at hand.

The revelation of information is described by $\left(\mathcal{F}_{t}\right)_{t \in[0,1]}$, the filtration generated by the random vector process $\tilde{N}(t) \equiv\left(N_{i}(t)\right)_{i=1}^{n}$, i.e. let $\sigma(x)$ denote the sigmaalgebra generated by the random variable $x$, then for each $t \in[0,1]$, let $\mathcal{F}_{t}$ be the $\sigma$-algebra representing all the information embodied in the vector process $\tilde{N}$ up to and including date $t$, i.e. $\mathcal{F}_{t}=\cap_{s \leq t} \sigma(\tilde{N}(s))$. Note that $\left\{\tau_{i}=\infty\right\}=\left\{N_{i}(1)=\right.$ $0\} \in \mathcal{F}_{1}$. A process $x(t)$ is said to be adapted to $\left(\mathcal{F}_{t}\right)_{t \in[0,1]}$ if for all $t, x(t)$ is $\mathcal{F}_{t^{-}}$ measurable. A process $x(t)$ is said to be $\left(\mathcal{F}_{t}\right)_{t}$-predictable if $x(t)$ is measurable with respect to $\mathcal{F}_{t-} \equiv \cap_{s<t} \sigma(\tilde{N}(s))$. Let $x(t-)$ denote $\lim _{s \uparrow t} x(s)$. A process $x(t)$ is said to be $\left(P,\left(\mathcal{F}_{t}\right)_{t \in[0,1]}\right)$-integrable if $x(t)$ is measurable with respect to $\mathcal{F}_{t-}$ and for all $t \int|x(t)| P(\mathrm{~d} \omega)<\infty$.

Future claims, $d$ are $\mathcal{F}_{1}$-measurable random variables. The price process $S(t)$ $t \in[0,1]$ is a stochastic price process adapted to $\left(\mathcal{F}_{t}\right)_{t \in[0,1]}$ such that $S(1)=d$.

In an economy with $J$ assets, let $\mathcal{D}=\left(\left(S_{j}(t)\right)_{t \in[0,1]}\right)_{j=1}^{J}$ and $\Theta$ denote the vector of allowable trading strategies given $\mathcal{D}$. In the usual way, an allowable trading strategy on asset $j$ is an $\mathcal{F}_{t}$-predictable and $\left(P, \mathcal{F}_{t}\right)$-integrable stochastic process 
$\theta_{j}$. To simplify notation in the text we have included the self-financing condition from the budget constraint into the definition of allowable strategies, i.e. $\theta \in \Theta$ implies

$$
\sum_{j=0}^{J} \theta_{j}(t) S_{j}(t)=\sum_{j=0}^{J} \theta_{j}(0) S_{j}(0)+\sum_{j=0}^{J} \int_{0}^{t} \theta_{j}(s) \mathrm{d} S_{j}(s), \quad \forall t \in[0,1] .
$$

\section{A.2. MARTINGALE DIMENSION}

Duffie and Huang(1985) show how to decentralize a state-contingent (AD) equilibrium as a Radner equilibrium if you have one riskless asset plus $K$ appropriate risky assets (see the original for the exact definition of 'appropriate'). The number $K$ is equal to the dimension of the space of $\left(Q,\left(\mathcal{F}_{t}\right)_{t \in[0,1]}\right)$-martingales, where a martingale is an $\mathcal{F}_{t}$-adapted and integrable process $X(t)$ such that $X(t)=E_{Q}\left[X(s) \mid \mathcal{F}_{t}\right]$ for all $0 \leq t \leq s \leq 1$, and $E_{Q}\left[y \mid \mathcal{F}_{t}\right]$ represents the expectation of random variable $y$ conditional on the sigma algebra $\mathcal{F}_{t}$ using probability measure $Q$. This measure $Q$ is derived from the equilibrium price of the $\mathrm{AD}$ equilibrium one is trying to decentralize (in Appendix A.4 we construct one such measure).

Take economy $\mathcal{E}(B)$. Equation (1) plus the conditions on preferences and endowments imply that $Q(\omega)=\xi(\omega) P(\omega)$ where $\xi(\omega)>0 P$-a.s. so that $Q$ is absolutely continuous relative to $P$. Fortunately, the martingale dimension of the space is invariant to an absolutely continuous change of measure so that it suffices to show:

Lemma A.1. The space of martingales on $\left(\Omega^{\prime}, \mathcal{F}_{1},\left(\mathcal{F}_{t}\right)_{t}, P\right)$ has martingale dimension of $n$.

Proof The martingale dimension is given by the minimal number of martingales, $M_{1}, \ldots, M_{K}$, that have the property that for any $\left(\mathcal{F}_{t}, P\right)$-martingale there exists $\left(\mathcal{F}_{t}, P\right)$ integrable and predictable vector process $y$ such that given $M=\left(M_{1}, \ldots, M_{K}\right)$,

$$
X(t)-X(0)=\int_{0}^{t} y(s) \mathrm{d} M(s)
$$


Let $\tilde{\lambda}=\left(\lambda_{1}, \ldots, \lambda_{n}\right)$, where for $j=1, \ldots, n, \lambda_{j}=\lambda$ for $N_{j}(t-)=0$ and zero otherwise. For $j=1, \ldots, n$, let $M_{j}(t)=\int_{0}^{t} \tilde{\lambda}_{j} \mathrm{~d} s-N_{j}(t)$ and $M(t)=\left(M_{j}(t)\right)_{j=1}^{n}$.

From the martingale representation theorem for marked point processes (see Last and Brandt(1991, pp. 342-346) for a general version and proof of this theorem), for every $\left(P,\left(\mathcal{F}_{t}\right)_{t}\right)$-martingale, $X(t)$, there exists a $\left(P,\left(\mathcal{F}_{t}\right)_{t \in[0,1]}\right)$-integrable predictable process $y(t)$ such that equation (A.1) holds. It is quite straightforward to show that $M_{j}(t)$ is a $\left(P, \mathcal{F}_{t}\right)$-martingale. Furthermore, they are pairwise orthogonal, so that the vector $M$ is minimal. Hence, the martingale dimension is equal to $n$.

\section{A.3. PROOF OF THEOREM 2.1 AND COROLLARY 2.1}

Proof: The agent's problem is

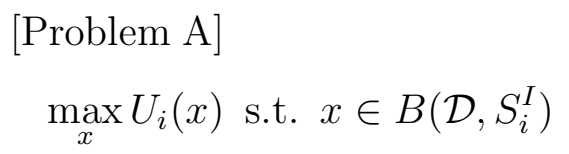

Let $x^{*}$ be maximal in the alternative problem

[Problem B]

$$
\max _{x} U_{i}(x) \quad \text { s.t. } \quad x^{*}(0)+E_{Q}\left[x^{*}(1)\right] e^{-\mathbf{r}}=e_{i}(0)+E_{Q}\left[e_{i}(1)\right] e^{-\mathbf{r}},
$$

where $Q$ and $r(t)$ are defined in the statement of Theorem 2.1. We proceed by proving the following three statements: (1) $x^{*}(1)=f(e(1)),(2) x \in B\left(\mathcal{D}, S_{i}^{I}\right) \Rightarrow$ $x$ satisfies the constraint in problem $\mathrm{B}$, and (c) $x^{*} \in B\left(\mathcal{D}, s_{i}^{I}\right)$ and is optimal. We drop the $i$ subscript for clarity.

(a). The problem B has Lagrangian

$$
L=U(x)-\lambda\left(x(0)+E_{Q}[x(1)] e^{-\mathbf{r}}-e_{i}(0)+S^{I} L-w e^{-\mathbf{r}}\right)
$$

The first order condition is:

$$
\begin{aligned}
v^{\prime}(x(0)) & =\lambda \\
\forall \omega \in \Omega^{\prime}, \beta u^{\prime}(x(1, \omega)) & =\lambda \xi(e(1, \omega)) e^{-\mathbf{r}}
\end{aligned}
$$


where $\lambda$ is the Lagrange multiplier in the constrained maximization problem. The properties of $u$ ensure that $u^{\prime-1}$ is a well-defined function so that we can define $x^{*}(1)=f(e(1))$ as:

$$
f(e(1)) \equiv u^{\prime-1}\left(\frac{v^{\prime}\left(x^{*}(0)\right) \xi(e(1)) e^{-\mathbf{r}}}{\beta}\right)
$$

where $x^{*}(0)$ is the constant that solves

$$
x^{*}(0)+E_{Q}[f(e(1))] e^{-\mathbf{r}}=e_{i}(0)-S_{i}^{I} L+e^{-\mathbf{r}} e_{i}(1)
$$

The properties of the problem $\left(u_{i}, v_{i}\right.$ increasing concave differentiable functions satisfying Inada conditions plus the linearity of the constraint) imply that such a $x^{*}(0)$ exists.

(b). By conditions (ii) and (iii) of Theorem 2.1, for $x \in B\left(\mathcal{D}, S_{i}^{I}\right)$ there exist $\alpha$ and $\theta$ such that

$$
\begin{gathered}
\left\{\begin{array}{l}
x(0)=e_{i}(0)-\alpha S^{I}-\sum_{j=0}^{J} \theta_{j}(0) S_{j}(0) \\
x(1)=e_{i}(1)+\alpha N_{i}(1)+\sum_{j=0}^{J}\left(\theta_{j}(0) S_{j}(0)+\int_{0}^{1} \theta_{j}(s) \mathrm{d} S_{j}(s)\right)
\end{array}\right. \\
\Rightarrow x(0)=e_{i}(0)-\alpha E_{Q}\left[N_{i}(1)\right] e^{-\mathbf{r}}-\sum_{j=0}^{J} \theta_{j}(0) S_{j}(0) \\
x(0)=e_{i}(0)+E_{Q}\left[e_{i}(1)-x(1)\right] e^{-\mathbf{r}}
\end{gathered}
$$

(c). We can write $x^{*}$ as

$$
\begin{gathered}
x^{*}(0)=e_{i}(0)-\alpha_{i} S_{i}^{I}-c \\
x^{*}(1)=w_{1}-\left(L-\alpha_{i}\right) N_{i}(1)+\tilde{x}(1)
\end{gathered}
$$

If we let $\alpha_{i}=L$, then $x^{*}(1)=w_{1}+\tilde{x}(1)$. By the premise of Theorem 2.1 there exists $\theta$ such that $\tilde{x}(1)=\sum_{j=0}^{J} \theta_{j}(0) S_{j}(0)+\int_{0}^{1} \sum_{j=0}^{J} \theta(s) \mathrm{d} S_{j}(s)$. Hence, if we let $c=\sum_{j} \theta_{j}(0) S_{j}(0)$, then $x^{*} \in B\left(\mathcal{D}, S_{i}^{I}\right)$. As $x^{*}$ is optimal in problem B and every other $x \in B\left(\mathcal{D}, S^{I}\right)$ is feasible in problem $\mathrm{B}$ then $x^{*}$ is optimal in the more 
restricted problem, A.

Theorem 2.1: Step (c) shows that full insurance $\left(\alpha_{i}=L\right)$ is used in constructing the strategy used to attain the (Problem $\mathrm{A}$ )-optimal $x^{*}$.

Corollary 2.1: As the insurance decision is always the same $\left(\alpha_{i}=L\right)$, it is independent of $\theta$ used to attain $\tilde{x}(1)$.

\section{A.4. PROOF OF THEOREMS 3.1 AND 4.1}

Theorem 3.1 can be proven using abstract martingale representation arguments (see Duffie Huang(1985) and Penalva(2001)). We complement their arguments by explicitly constructing the strategies for the proof of Theorem 3.1 in the proof of Theorem 4.1 (thereby embedding the proof of Theorem 4.1 in the proof of Theorem 3.1).

Proof of Theorem 3.1: we proceed to construct the equilibrium in stages: (1) We show that a stage-contingent equilibrium exists and define asset and insurance prices $\left(\mathcal{D},\left(S_{i}^{I}\right)_{i=1}^{n}\right)$ using state-contingent equilibrium prices; (2) we show that the state-contingent equilibrium consumption allocations are in the agent's budget constraint, $B\left(\mathcal{D}, S_{i}^{I}\right)$, by constructing the appropriate trading strategies; (3) we show optimality of the allocations.

Stage 1. Let $\mathcal{E}$ denote an economy with $n$ agents indexed by $i$, with common priors (given by the measure $P$ ), preferences of the form

$$
U_{i}(x)=u_{i}(x(0))+\beta_{i} E_{P}\left(v_{i}(x(1))\right),
$$

with $u_{i}$ and $v_{i}$ are concave, differentiable and satisfying the standard Inada conditions, $\beta_{i} \in(0, \infty)$, and endowments $e_{i}=\left(e_{i}(0), e_{i}(1)\right)$ such that $\sum_{i} e_{i}(t)>0$ for $t \in\{0,1\}$. We use the following well-known result (for example, Constantinides(1982)).

Lemma A.1. For any $A D$ equilibrium of $\mathcal{E},\left(\left(x_{i}^{*}\right)_{i=1}^{n}, \tilde{\pi}\right)$, there exists a representative agent representation of prices with strictly concave vonNeumann- 
Morgenstern preferences

$$
v_{0}(x(0))+\beta_{0} E_{P}\left[v_{1}(x(1))\right]
$$

such that

$$
\forall \omega \in \Omega, \tilde{\pi}(\omega)=\frac{\beta_{0} v_{1}^{\prime}(e(1))}{v_{0}^{\prime}(e(0))}
$$

where $v_{t}^{\prime}(x)$ is the first derivative of the representative agent's utility function at date $t=0,1$. For all $i$, there exists $f_{i}: \mathbf{R} \rightarrow \mathbf{R}$ such that $x_{i}^{*}(1)=f_{i}(e(1))$.

From this equilibrium, define $Q$ and $r$ for the insurance market equilibrium as:

$$
Q(\omega)=\frac{\tilde{\pi}(\omega)}{\int_{\omega \in \Omega} \tilde{\pi}(\omega) \mathrm{d} \omega}
$$

Let $P_{t}$ and $Q_{t}$ define the restriction to $\left(\Omega, \mathcal{F}_{t}\right)$ of $P$ and $Q$ respectively. Define the Radon-Nikodym derivative process as

$$
\begin{gathered}
Q(\omega)=P(\omega) \xi(1, \omega) ; \quad \xi(t, \omega)=\frac{\xi(1, \omega)}{E_{P}\left[\xi(1) \mid \mathcal{F}_{t}\right](\omega)} \equiv \frac{\mathrm{d} Q_{t}}{\mathrm{~d} P_{t}}(\omega) \\
e^{-\mathbf{r}} \equiv \int_{\omega \in \Omega} \tilde{\pi}(\omega) ; \quad \exp \left(-\int_{t}^{1} r(s) \mathrm{d} s\right) \equiv e^{-\mathbf{r}(1-t)}
\end{gathered}
$$

Define $\mathcal{D}=\left(S_{0}(t), S_{M}(t)\right)$ as follows: for all $t \in[0,1)$

$$
\begin{gathered}
S_{0}(t)=\exp \left(-\int_{t}^{1} r(s) \mathrm{d} s\right) \\
S_{M}(t)=\frac{1}{J} S_{j}(t)
\end{gathered}
$$

where the price of a share in firm $j$ is the market value of the insurance company's assets (the premia collected plus interest) minus the market value of the liabilities (future indemnities):

$$
S_{j}(t)=\sum_{i \in I_{j}} \alpha_{i} S_{i}^{I} e^{\mathbf{r} t}-E_{Q}\left[\sum_{i \in I_{j}} \alpha_{i} N_{i}(1) e^{-\mathbf{r}(1-t)} \mid \mathcal{F}_{t}\right]
$$

Let $S_{i}^{I}=E_{Q}\left[N_{i}(1)\right] e^{-\mathbf{r}}$ - this implies that for any insurance company $S_{j}(0)=0$. 
Stage 2. We want to check whether $x_{i}^{*} \in B\left(\mathcal{D}, S_{i}^{I}\right)$. From Lemma A.2, for all $i=1, \ldots, n, x_{i}^{*}(1)=f_{i}(e(1))$. As $e(1)=n w-N(1) L$, and abusing the $f$ notation $x_{i}^{*}(1)=f_{i}(N(1))$. We need to show that $x_{i}^{*}(1)$ can be achieved using a dynamic trading strategy with only the bond and the portfolio. We can appeal to martingale representation theorems, as in Penalva (2001) and Duffie Huang (1985), to show that such dynamic trading strategies exists. We proceed by constructing those strategies.

Stage 2.a We first look at the aggregate process $N(t)$. Consider the general case, $\lambda_{i}(t)=g(t, N(t-)) \mathbf{1}_{N_{i}(t-)=0}$, where $g: \mathbf{R} \times \mathbf{N} \longrightarrow \mathbf{R}$ with $g(t, N(t-))=\lambda$ as a special case. Let $\lambda^{N}(t)=\sum_{i=1}^{n} \lambda_{i}(t)$. Then

$$
\begin{aligned}
\lambda^{N}(t) & =\sum_{i=1}^{n} g(t, N(t-)) \mathbf{1}_{N_{i}(t-)=0}=g(t, N(t-)) \sum_{i=1}^{n} \mathbf{1}_{N_{i}(t-)=0} \\
& =g(t, N(t-)) N(t-)
\end{aligned}
$$

and we can say that $N(t)$ admits the $\mathcal{F}_{t}$-intensity $\lambda^{N}$ (see Brémaud for a detailed exposition of these concepts and related results).

Stage 2.b We now turn to the price process for the portfolio. Define the discounted price of the portfolio as $S_{M}^{*}$ :

$$
\begin{aligned}
S_{M}^{*}(t) & \equiv \sum_{j=1}^{J} \frac{1}{J} S_{j}^{*}(t)=\sum_{j=1}^{J} \frac{1}{J} e^{-\mathbf{r} t} S_{j}(t) \\
& =e^{-\mathbf{r} t}\left(\sum_{j=1}^{J} \frac{1}{J}\left(\sum_{i \in I_{j}} \alpha_{i} S_{i}^{I} e^{\mathbf{r} t}-E_{Q}\left[\sum_{i \in I_{j}} \alpha_{i} N_{i}(1) e^{-\mathbf{r}(1-t)} \mid \mathcal{F}_{t}\right]\right)\right)
\end{aligned}
$$

Let $C_{j}=\sum_{i \in I_{j}} \alpha_{i} S_{i}^{I} / J$. If $\alpha_{i}=L$ for all $i$, then

$$
\begin{aligned}
S_{M}^{*}(t) & =e^{-\mathbf{r} t}\left(\sum_{j=1}^{J} C_{j} e^{\mathbf{r} t}-\frac{L}{J} E_{Q}\left[N(1) e^{-\mathbf{r}(1-t)} \mid \mathcal{F}_{t}\right]\right) \\
& =\sum_{j=1}^{J} C_{j}-\frac{L}{J} E_{Q}\left[N(1) \mid \mathcal{F}_{t}\right] e^{-\mathbf{r}}
\end{aligned}
$$

Let $C=L / J$. Similarly, for $x(1)$ define

$$
X^{*}(t) \equiv e^{-\mathbf{r} t} E_{Q}\left[x_{i}^{*}(1) e^{-\mathbf{r}(1-t)} \mid \mathcal{F}_{t}\right]=E_{Q}\left[x_{i}^{*}(1) \mid \mathcal{F}_{t}\right] e^{-\mathbf{r}}
$$


Stage 2.c We want to identify how we will replicate $X^{*}(t)$ using the portfolio, $S_{M}^{*}$. Using martingale representation arguments as in Penalva (2001) we know that such a portfolio exists. In order to construct it we use that for $\theta_{M}^{i}(t) \in \Theta$ (we drop the $i$ superscripts for the rest of the proof)

$$
\left\{\begin{array}{l}
\theta_{M}(0) S_{M}^{*}(0)=X^{*}(0) \\
\theta_{M}(t) S_{M}^{*}(t)=X^{*}(t) \\
\theta_{M}(t) S_{M}^{*}(t)=\theta_{M}(0) S_{M}^{*}(0)+\int_{0}^{t} \theta_{M}(s) \mathrm{d} S_{M}^{*}(s)
\end{array}\right.
$$

So that to construct $\theta_{M}$ we need to solve

$$
\mathrm{d} X^{*}(t)=\theta_{M}(t) \mathrm{d} S_{M}^{*}(t)
$$

From $x_{i}^{*}(1)=f_{i}(N(1))$ and the definitions of $X^{*}$ and $S_{M}^{*}$ :

$$
\begin{aligned}
\mathrm{d} X^{*}(t) & =e^{-\mathbf{r}} \mathrm{d}\left(E_{Q}\left[x_{i}^{*}(1) \mid \mathcal{F}_{t}\right]\right) \\
& =e^{-\mathbf{r}} \mathrm{d}\left(E_{Q}\left[f_{i}(N(1)) \mid \mathcal{F}_{t}\right]\right) \\
\& \mathrm{~d} S_{M}^{*}(t) & =-e^{-\mathbf{r}} C \mathrm{~d} E_{Q}\left[N(1) \mid \mathcal{F}_{t}\right]
\end{aligned}
$$

So that to replicate $X^{*}$ we need to solve

$$
\mathrm{d} E_{Q}\left[f_{i}(N(1)) \mid \mathcal{F}_{t}\right]=-\theta_{M}(t) C \mathrm{~d} E_{Q}\left[N(1) \mid \mathcal{F}_{t}\right]
$$

Stage 2.d We want to use the properties of $E_{Q}\left[y \mid \mathcal{F}_{t}\right]$ for arbitrary $y=y(N(1))$.

$$
\begin{aligned}
E_{Q}\left[y \mid \mathcal{F}_{t}\right] & =\frac{E_{P}\left[\xi(t) y \mid \mathcal{F}_{t}\right]}{E_{P}\left[\xi(1) \mid \mathcal{F}_{t}\right]} \\
& =\sum_{k=N(t)}^{n} \frac{P\left\{N(1)=k \mid \mathcal{F}_{t}\right\} \xi(1) y}{E_{P}\left[\xi(1) \mid \mathcal{F}_{t}\right]}
\end{aligned}
$$

As $\lambda^{N}$ is a function only of $t$ and $N(t-)$, the probability $P\left\{N(1)=k \mid \mathcal{F}_{t}\right\}$ is only a function of $N(t), k$ and $t$ so that for $N(t)=N, P\left\{N(1)=k \mid \mathcal{F}_{t}\right\}=\mathcal{P}(t, k, N)$. This function can be easily constructed recursively for time homogenous hazards, i.e. $\lambda^{N}(t, N(t-))=N(t-) g(N(t-))$, (using the shorthand $\left.\lambda_{k}=\lambda^{N}(t, k)\right)$ as:

$$
\begin{aligned}
\mathcal{P}(t, k, k) & =\exp \left(-\lambda_{k}(1-t)\right) \\
\mathcal{P}(t, j+1, k) & =\int_{t}^{1} \mathcal{P}(t+s, j, k) \lambda_{j} \exp \left(-\lambda_{j+1}(1-s)\right) \mathrm{d} s, j=k, \ldots, n-1
\end{aligned}
$$


This definition is extended to the non-time homogenous case by using $\lambda_{j}(s)=$ $\lambda^{N}(s, j)$ and substituting $\lambda_{j}(1-t)$ (and $\lambda_{j+1}(1-s)$ ) with $\int_{t}^{1} \lambda_{j}(u) \mathrm{d} u\left(\right.$ and $\left.\int_{s}^{1} \lambda_{j+1}(u) \mathrm{d} u\right)$ in the above equations. Note that for the independence case, $\lambda^{N}=N(t-) \lambda$, $\mathcal{P}(t, k, N)$ is given by the binomial probability of $k-N$ successes out of $n-N$ trials with probability of success $p(t)=1-\exp (-\lambda(1-t))$.

Using these definitions

$$
\begin{aligned}
& E_{Q}\left[y \mid \mathcal{F}_{t}\right]=\sum_{k=N(t)}^{n} \frac{\mathcal{P}(t, k, N(t)) \xi(1, k) y(k)}{E_{P}\left[\xi(1) \mid \mathcal{F}_{t}\right]} \\
& \text { and } \xi(t)=\frac{\xi(1)}{E_{P}\left[\xi(1) \mid \mathcal{F}_{t}\right]}
\end{aligned}
$$

Given the properties of $\xi(1)$ and $\mathcal{P}$ (and abusing notation) we can define deterministic functions $\xi(1, N)$ and $\xi(t, j, N)$ :

$$
\begin{aligned}
\forall j, k \in\{0,1, \ldots, n\} & \\
\xi(1, k) & =\xi(1, \omega) \mathbf{1}_{N(1, \omega)=k} \\
\forall t \in[0,1), \xi(t, j, k) & = \begin{cases}\frac{\xi(1, j)}{\sum_{s=k}^{n} \mathcal{P}(t, s, k) \xi(1, s)} & n \geq j \geq N \\
0 & \text { otherwise }\end{cases} \\
\Rightarrow E_{Q}\left[y \mid \mathcal{F}_{t}\right] & =\sum_{j=0}^{n} \mathbf{1}_{\{N(t)=j\}}\left(\sum_{k=j}^{n} \mathcal{P}(t, k, j) \xi(t, k, j) y(k)\right)
\end{aligned}
$$

Equation (A.4) must hold at all accident times. For arbitrary adapted process $x(t)$ let $\Delta x(t)=(x(t-)-x(t)) \mathbf{1}_{\{N(t)-N(t-)=1\}}$. As $\theta_{M}(t)$ has to be predictable, then the following equation characterizes $\theta_{M}(t)$

$$
\Delta E_{Q}\left[f_{i}(N(1)) \mid \mathcal{F}_{t}\right]=-\theta_{M}(t) C \Delta E_{Q}\left[N(1) \mid \mathcal{F}_{t}\right]
$$

We use equation (A.5) to define $n+1$ deterministic functions $\hat{\theta}_{M}(t, k), k=$ $0, \ldots, n$. Let $\hat{\theta}_{M}(t, n)=0$ and for $k \in\{0, \ldots, n-1\}$ define

$\hat{\theta}_{M}(t, k)=\frac{1}{C} \frac{\sum_{j=k}^{n} \mathcal{P}(t, j, k) \xi(t, j, k) f_{i}(j)-\sum_{j=k+1}^{n} \mathcal{P}(t, j, k+1) \xi(t, j, k+1) f_{i}(j)}{\sum_{j=k}^{n} \mathcal{P}(t, j, k) \xi(t, j, k) j-\sum_{j=k+1}^{n} \mathcal{P}(t, j, k+1) \xi(t, j, k+1) j}$ 
As $\theta_{M}$ has to be predictable and equation (A.5) has to hold then

$$
\theta_{M}(t)=\sum_{j=0}^{n} \mathbf{1}_{\{N(t-)=j\}} \hat{\theta}_{M}(t, j)
$$

Stage 2.e We now define the strategies on the bond, $\theta_{0}(t)$. Define $S_{0}^{*}(t)=$ $e^{-\mathbf{r} t} S_{0}(t)=e^{-\mathbf{r}}$ and let

$$
\theta_{0}(t)=\frac{X^{*}(t)-\theta_{M}(t) S_{M}^{*}(t)}{S_{0}^{*}(t)}
$$

Note that $\theta_{0}(t)$ is predictable and positive because $S_{0}^{*}(t)$ is predictable by construction plus the definition of $\theta_{M}(t)$ makes $X^{*}(t)-\theta_{M}(t) S_{M}^{*}(t)$ predictable. From the previous stage it is clear that the above equation can be expressed using deterministic functions $\hat{\theta}_{0}(t, k)$ such that

$$
\theta_{0}(t)=\sum_{k=0}^{n} \mathbf{1}_{\{N(t-)=k\}} \hat{\theta}_{0}(t, k)
$$

Stage 2.f Finally, we need to show that $x_{i}^{*} \in B\left(\mathcal{D}, S_{i}^{I}\right)$. To obtain $x_{i}^{*}$, the agent can buy full insurance $\left(\alpha_{i}=L\right)$ and trade dynamically the mutual fund using the strategy $\theta_{M}(t)$ defined above, and trade dynamically the bond but using $\tilde{X}(t)=X^{*}(t)-w_{1, i} e^{-\mathbf{r}}$ instead of $X^{*}$. Following this strategy leaves the agent with the following consumptions:

$$
\begin{aligned}
c(0) & =w_{i, 0}-S_{i}^{I} L-\theta_{M}(0) S_{M}(0)-\theta_{0}(0) S_{0}(0) \\
& =w_{i, 0}-S_{i}^{I} L-\theta_{M}(0) S_{M}(0)-\frac{\tilde{X}(0)-\theta_{M}(0) S_{M}^{*}(0)}{S_{0}^{*}(0)} S_{0}(0)
\end{aligned}
$$

Recall $S_{0}^{*}(0)=e^{-\mathbf{r}}=S_{0}(0), S_{M}^{*}(0)=E_{Q}\left[d_{M}\right] e^{-\mathbf{r}}=S_{M}(0)$, and $\tilde{X}(0)=$ $E_{Q}\left[x_{i}^{*}(1)-w_{i, 1}\right] e^{-\mathbf{r}}$. Also, recall the definitions of $Q$ and $r$ from Stage 1. As $x_{i}^{*}$ satisfies the state-contingent commodity budget constraint

$$
\begin{aligned}
c(0) & =w_{i, 0}-S_{i}^{I} L-E_{Q}\left[x_{i}^{*}(1)\right] e^{-\mathbf{r}}+w_{i, 1} e^{-\mathbf{r}} \\
& =x_{i}^{*}(0)
\end{aligned}
$$

As for the consumption obtained from this strategy at date one:

$$
\begin{aligned}
c(1) & =w_{i, 1}-N_{i}(1)\left(L-\alpha_{i}\right)+\theta_{M}(1) S_{M}(1)+\theta_{0}(1) S_{0}(1) \\
& =w_{i, 1}+\theta_{M}(1) S_{M}(1)+\frac{\tilde{X}(1)-\theta_{M}(1) S_{M}^{*}(1)}{S_{0}^{*}(1)} S_{0}(1)
\end{aligned}
$$




$$
\begin{aligned}
& =w_{i, 1}+\theta_{M}(1) d_{M}(1)+\frac{\left(x_{i}^{*}(1)-w_{i, 1}\right) e^{-\mathbf{r}}-\theta_{M}(1) d_{M}(1) e^{-\mathbf{r}}}{e^{-\mathbf{r}}} \times 1 \\
& =x_{i}^{*}(1)
\end{aligned}
$$

Stage 3. As shown in the proof of Theorem 2.1, all consumption allocations in $B\left(S_{i}^{I}, \mathcal{D}\right)$ are also feasible in the state-contingent budget constraint so that $x_{i}^{*}$ is also optimal in the insurance market equilibrium.

Theorem 4.1: The reader will find the strategies characterized and constructed in Stages 2.d and 2.e of the previous proof. In Stage 2.f it is shown that those strategies do indeed attain the desired equilibrium allocations.

\section{A.5. PROOF OF THEOREM 4.2}

We prove the result in a more general way using the concept of exchangeability. Let $B_{i}$ represent an event of the form $\left\{N_{i}(1)=0\right\}$ or $\left\{N_{i}(1)=1\right\}$ and $A_{i}=$ $\left\{N_{i}(1)=1\right\}$. Also, let $\mathbf{1}_{A}$ denote the indicator function of an arbitrary event $A$.

Remark A. 1. If $\lambda_{i}(t)=g(t, N(t)) \mathbf{1}_{\left\{N_{i}(t-)=0\right\}}$, where $g: \mathbf{R} \times \mathbf{N} \longrightarrow \mathbf{R}$, then the events $B_{1}, B_{2}, \ldots, B_{n}$ are exchangeable events, i.e. for all permutations of the indeces, $\iota(n):\{1, \ldots, n\} \longrightarrow\{1, \ldots, n\}, \iota$ a one-to-one function,

$$
P\left(B_{1}, B_{2}, \ldots, B_{n}\right)=P\left(B_{\iota(1)}, B_{\iota(2)}, \ldots, B_{\iota(n)}\right)
$$

That this is true can be seen from the way the function $\mathcal{P}$ was constructed in Appendix A.4

Exchangeability implies that for $i, j, k \in\{1, \ldots, n\}, P\left(A_{i}\right)=P\left(A_{k}\right)=p$ and

$$
\begin{aligned}
P\left(N=j, N_{i}=1\right) & =P\left(N=j, N_{k}=1\right) \\
& =P(N=j)\left(\begin{array}{l}
n-1 \\
j-1
\end{array}\right) /\left(\begin{array}{l}
n \\
j
\end{array}\right)=P(N=j) \frac{j}{n}
\end{aligned}
$$

Let $q_{i}=E_{Q}\left[A_{i}\right], \xi=\mathrm{d} Q / \mathrm{d} P$ and recall $n$ is finite, then

$$
q_{i}=\sum_{\omega \in A_{i}} P(\omega) \xi(\omega)
$$




$$
\begin{aligned}
q_{i} & =\sum_{j=0}^{n} P\left(N=j \mid A_{i}\right) P\left(A_{i}\right) \xi(N=j) \\
q_{i} & =p E_{P}\left[\xi(N(1)) \mid A_{i}\right]
\end{aligned}
$$

and by exchangeability, $q_{i}=p E_{P}\left[\xi \mid A_{k}\right], \forall k \in\{1, \ldots, n\}$, so that for all $i=$ $1, \ldots, n, q_{i}=q$. Let $p_{j} \equiv P(N=j)$, then

$$
P\left(N=j \mid A_{i}\right)-P(N=j)=\frac{p_{j}}{p} \frac{j}{n}-p_{j}=\frac{p_{j}}{n p}(j-n p)
$$

Using $p=\sum_{k=0}^{n} P\left(N=k, A_{i}\right)$ and $P\left(N=k, A_{i}\right)=p_{k} k / n$

$$
\begin{aligned}
P\left(N=j \mid A_{i}\right)-P(N=j) & =\frac{p_{j}}{n p}\left(j-n \sum_{k=0}^{n} p_{k} \frac{k}{n}\right) \\
& =\frac{p_{j}}{n p}(j-E[N])
\end{aligned}
$$

As $E[(j-E[N])]=0$ and $N$ is increasing, then for all $k \leq n$

$$
F_{N \mid A_{i}}(k) \equiv \sum_{j=0}^{k} P\left(N=j \mid A_{i}\right) \leq F_{N}(k) \equiv \sum_{j=0}^{k} P(N=j)
$$

and the inequality is strict at least for $N=0$. That is, $N(1) \mid A_{i}$ first-order stochastically dominates ${ }^{1} N(1)$. The economy has a representative agent representation with strictly increasing and concave utility (see Lemma A.1) so that the equilibrium $\xi(N)$ will be strictly increasing. By definition $E[\xi]=1$. Stochastic dominance of $F_{N \mid A_{i}}, \xi$ increasing, and $E_{P}[\xi]=1$ imply $E_{P}\left[\xi \mid A_{i}\right]>1$ and $q>p$.

$$
S=E_{Q}\left[N_{i}(1)\right] e^{-\mathbf{r}}=q e^{-\mathbf{r}}=p(1+\gamma) e^{-\mathbf{r}}
$$

with $\gamma>0$.

\section{REFERENCES}

1. Aase, Knut K. (2001): "A Markov Model for the Pricing of Catastrophe Insurance Futures and Spreads", Journal of Risk and Insurance, 68(1), 25-49.

2. Arrow, Kenneth J. (1964): "The Role of Securities in the Optimal Allocation of Risk-bearing," Review of Economic Studies, 31(2), pp. 91-96 (reprinted

\footnotetext{
${ }^{1}$ The notion of first-order stochastic dominance is quite standard, see Huang and Litzenberger (1988) for a definition and more details.
} 
from Économétric (1953) published by the Centre Nationale de la Recerche Scientifique).

3. Borch, K. (1984): "Equilibrium Premiums in an Insurance Market," Journal of Risk and Insurance, 51(3), 468-76.

4. Brémaud, P. (1981): Point Processes and Queues: Martingale Dynamics., Springer-Verlag. New York.

5. Cass, David, Graciela Chichilnisky and Ho-Mou Wu (1996): "Individual Risk and Mutual Insurance," Econometrica, 64, 333-341.

6. Christensen, P. O., S. E. Graversen, and K. R. Miltersen (2001) "Dynamic Spanning in the Consumption-Based Capital Asset Pricing Model," European Finance Review, 4(2):129-156.

7. Constantinides, George M. (1982): "Intertemporal Asset Pricing with Heterogeneous Consumers and Without Demand Aggregation," Journal of Business, 55(2), 253-267.

8. Cummins, J.D. And Olivier Mahul (2001): "Optimal Insurance with Asymmetric Information About Insurer Default Risk" mimeo, Journal of Risk and Uncertainty, forthcoming.

9. Doherty, Neil A. And Georges Dionne (1993): "Insurance with Undiversifiable Risk: Contract Structure and Organizational Form of Insurance Firms," Journal of Risk and Uncertainty, 6(2), 187-203.

10. Doherty, Neil A. And S. M. Tiniç (1981): "Reinsurance under Conditions of Capital Market Equilibrium: A Note," Journal of Finance, 36(4), 949-953.

11. Doherty, N.A. And H. Schlesinger (1983): "Optimal insurance in incomplete markets," Journal of Political Economy, 91(6), 1045-1054.

12. Duffie, D. And C. Huang (1985): "Implementing Arrow-Debreu equilibria by continuous trading of few long-lived securities," Econometrica, 53, 13371356 .

13. Eeckhoudt, Louis And Mike Kimball (1991): "Background risk, prudence, and the demand for insurance," in G. Dionne, ed., Contributions to Insurance Economics, Amsterdam: Kluwer Academic Press.

14. Ellickson, B., And J. Penalva Zuasti (1997): "Intertemporal insurance," Journal of Risk and Insurance, 64(4), 579-598.

15. Froot, Kenneth A. (2001): "The Market for Catastrophe Risk: A Clinical Examination", sl Journal of Financial Economics, 60(2-3), 529-571.

16. Gollier, Christian (1994): "Insurance and Precautionary Capital Accumulation in a Continuous-Time Model," Journal of Risk and Insurance, 61(1), $78-95$

17. Harrington, Scott E. And Greg Niehaus (1999): "Basis Risk with PCS Catastrophe Insurance Derivative Contracts", Journal of Risk and Insurance, 66(1), 49-82.

18. Harrington, Scott E. And Greg Niehaus (2002): "Capital Structure Decisions in the Insurance Industry: Stocks versus Mutuals", Journal of Financial Services Research, 21(1-2), 145-163. 
19. Harrison, J. And D. Kreps (1979): "Martingales and arbitrage in Multiperiod Securities," Journal of Economic Theory, 20, 381-408.

20. Huang, Chi-fu And Robert H. Litzenberger (1988) Foundations for Financial Economics, North Holland.

21. Jaffee, Dwight M. And Thomas Russell (1997) "Catastrophe Insurance, Capital Markets, and Uninsurable Risks," Journal of Risk and Insurance, 64(2), 205-230.

22. Last, G. And A. Brandt (1995): Marked Point Processes on the Real Line: The Dynamic Approach., Springer-Verlag. New York.

23. Malinvaud, E. (1972): "The Allocation of Individual Risks in Large Markets," Journal of Economic Theory, 4, 312-328.

24. Malinvaud, E. (1973): "Markets for an Exchange Economy with Individual Risks," Econometrica, 41(3), 383-410.

25. Merton, R.C. (1969): "Lifetime portfolio selection under uncertainty: The continuous time case," Review of Economic Statistics, 51, 247-257.

26. Merton, R.C. (1971): "Optimum consumption and portfolio rules in a continuous time model," Journal of Economic Theory, 3, 373-413.

27. Penalva Zuasti, Jose S. (2001) Insurance with Frequent Trading: A Dynamic Analysis of Efficient Insurance Markets, Review of Economic Dynamics

28. RADNER, R. (1972): "Existence of equilibrium of plans, prices and price expectations in a sequence of markets," Econometrica, 40, 1365-1379.

29. Samuelson, P. (1969): "Lifetime portfolio selection by dynamic stochastic programming," Review of Economic Statistics 57, 239-246.

30. Smith, C.W. And D. Mayers (1983): "The Interdependence of Individual Portfolio Decisions and the Demand for Insurance," Journal of Political Economy, 91(2), 304-311.

31. Vercammen, James (2001) "Optimal Insurance with Nonseparable Background Risk," Journal of Risk and Insurance, 68(3), 437-447.

32. Zanjani, George (2002): "Pricing and Capital Allocation in Catastrophe Insurance" Journal of Financial Economics, 65(2), 283-305 